\title{
Neka zapažanja o etnojezičkoj situaciji u dvojezičnim makedonsko-albanskim selima u regionu Prespa: fenomen Arvati*
}

\author{
A. L. MAKAROVA \\ Институт лингвистических исследований, Российской академии наук, \\ Тучков пер., д. 9, RU-199053 Санкт-Петербург \\ E-mail: abeatina@rambler.ru
}

(Received: 14 January 2016; accepted: 28 March 2016)

\begin{abstract}
This paper provides an analysis of the language situation in the villages of the multi-ethnic Prespa region (Republic of Macedonia): Krani and Arvati. The language situation in these villages appears to be especially noteworthy in juxtaposition with the general language situations in Republic of Macedonia. Interestingly, the local bilingualism has no religion restrictions, so Orthodox Macedonians master Albanian language, which is unusual for other Macedonian regions. The most significant features of the Prespa language situation are the following: 1) a relatively high degree of linguistic competence of Macedonian informants in the Albanian language; 2) the young age of second language acquisition; 3) the use of the Albanian language as a primary means of communication within the village; 4) the absence of code-mixing in the narrative.
\end{abstract}

Keywords: ethnolinguistic situation, bilingualism, Macedonian, Albanian, dialectology, Prespa region, confessional limitations

\section{Etnojezička situacija u Republici Makedoniji}

U okviru ovog članka će se pod terminom etnojezička situacija podrazumevati (u skladu sa ruskom sociolingvističkom tradicijom), ,celokupnost formi postojanja jednog jezika ili celokupnost nekoliko jezika u njihovoj socijalnoj i funkcionalnoj uzajmnoj povezanosti u granicama određenih područja: regiona ili administrativnopolitičkih formacija" (ВАхтин-Головко 2004: 46-47). Termin jezička situacija se obično koristi u odnosu na relativno veće jezičke zajednice (države ili pokrajine) (БЕликов-Крысин 2000: 26) i na određene istorijske periode. U suštini jezička situacija je sinhronijski opis etnojezičke zajednice u određeno doba njenog postojanja (БЕликов-Крысин 2000: 27). U ovom se radu prikazuju neka zapažanja o funkcionisanju i uzajamnom delovanju standardnih i dijalekatskih formi jezika Albanaca i Makedonaca u donekle malom polietničkom području (predeo Prespanskog jezera), koja se odlikuju znatnom svojevrstnošću na fonu opšte etnojezičke situacije u Republici Makedoniji.

* Istraživanje je obavljeno uz podršku granta Ruskog naučnog fonda (projekat №14-18-01405 „От сепарации до симбиоза: языки и культуры Юго-Восточной Европы в контакте”). 
Jezička situacija u Republici Makedoniji se određuje uzajamnim postojanjem državnog jezika t.j. makedonskog (maternji za 66,5\% stanovništva, ca. 1,3 miliona stanovnika $)^{1}$ i jezika drugih etničkih zajednica odnosno albanskog $(22,9 \%$, ca. 450 hiljada ljudi), turskog (4\%, ca. 77 hiljada ljudi), romskog $(2,3 \%$, ca. 45 hiljada ljudi), $\operatorname{srpskog}(2 \%$, ca. 40 hiljada ljudi) i arumunskog $(0,4 \%$, ca. 9 hiljada ljudi) (HILL 2002: 295, KAHL 2005). Jezička situacija na području Vardarske Makedonije (od 1944. godine - Narodna Republika Makedonija u sastavu SFRJ, od 1991. godine Republika Makedonija) se tokom mnogih vekova odlikovala polilingvizmom i diglosijom. ${ }^{2}$ U različitim istorijskim periodima od doba dolaska Slovena na Balkan ulogu zvaničnog jezika je punio vizantijski grčki, starobugarski, osmanski turski, bugarski, novogrčki (isti se koristio u svojstvu jezika prosvete u devetnaestom veku), srpski odnosno srpskohrvatski (HILL 2002: 308-309).

Makedonija je polikonfesionalna država (DöPMAN 2005) što utiče i na neke činjenice jezičke situacije: Makedonci-muslimai (t. n. Torbeši) u delu regiona vladaju albanskim i/ili turskim jezikom što nije karakteristično za pravoslavne Makedonce koji u glavnom znaju samo makedonski (KAHL 2005: 59).

Politička dešavanja poslednjih godina (na primer ratni konflikt 2001. godine koji se završio podpisivanjem Ohridskog dogovora ${ }^{3}$ od 13. avgusta 2001. godine ORTAKOVSKI 2001) pokazuju da međuetnički odnosi u ovoj državi nisu nimalo mirni i stabilni. Albanci čine skoro četvrtinu celokupnog stanovništva Republike, to jest predstavljaju to je najveća etnička manjina. U maju 2015. godine se desila još jedna eskalacija međuetničkih suprotnosti. ${ }^{4}$

U svim gradovima na granici između Makedonije i Albanije Albanci čine većinu stanovništva, islam predstavlja najprošireniju religiju (KAHL 2005: 60, JUSUFI 2011: 1-30). Simbioza Albanaca i Makedonaca u Republici Makedoniji je povezana sa stalnom pretnjom separatizma sa jedne strane i opasnošću etničke diskriminacije i ksenofobije - sa druge (MEIER 2005: 170), kao što je i sa mnogobrojnim problemima i konfliktima u svim oblastima socijalnog i političkog života u državi, uključujući jezičku i prosvetnu politiku (DEMIRI 2005, SCHRAMEYER 2005). U toku zadnjih 15 godina posle proglašavanja nezavisnosti Makedonije ne prekida se borba albanske manjine za proširenje njenih prava. Albanska politička stranka zahteva posebni status albanskog naroda u Ustavu države, proširenje mogućnosti za sticanje srednjeg i visokog obrazovanja na albanskom jeziku, priznanje albanskog jezika kao drugog državnog), uvođenje lokalne samouprave u krajevima gde albansko čini većinu stanovništva i dr. (MEIER 2005). Danas, veliki deo ovih zahteva je ispunjen.

\footnotetext{
${ }^{1}$ Државен завод за статистика на Република Македонија (http://www.stat.gov.mk).

${ }^{2}$ Diglosija se ovde razume kao istovremeno postojanje dvaju jezika ili dveju forme jednog jezika koji se koriste u različitim funkcionalnim oblastima (ЯРЦЕВА 1990: 136).

${ }^{3}$ Tekst Ohridskog dogovora je dostupan na sajtu Evropskog Saveta: http://web.archive.org/ web/20070113074850/http://www.coe.int/t/e/legal_affairs/legal_co-operation/police_and_internal_ security/OHRID\%20Agreement $\% 2013$ august2001.asp.

${ }^{4}$ Informacija je dostupna u medijama, na primer: http://www.bbc.co.uk/russian/international/ 2015/05/150509_macedonia_clashes.
} 


\section{Region Prespa}

Prespansko područje ${ }^{5}$ je danas podeljeno između Albanije, Grčke i Makedonije, ali sa što se tiče fizičke geografije predstavlja užu, autentičnu, geografski ograničenu kotlinu okruženu planinama sa svih strana i uključuje dva jezera Veliko Prespansko i Malo Prespansko jezero. Ovo područje je veoma raznovrsno u odnosu na etničke i konfesionalne zajednice koje tamo žive. Prespa je jedan od tipičnih primera minimalne antropogeografske teritorijalne jedinice: „Balkansko poluostrovo u svom planinskom delu obiluje malim kompaktnim geografski izolovanim, pogodnim za život predelima (doline i kotline), čije stanovništvo čini malobrojnu i relativno izolovanu grupu koja, međutim nije uvek jedinstvena u administrativno-političkom, ekonomskom, etnografskom, jezičkom i kulturnom smislu" (Соболев 2013: 94-107).

Već od ranog srednjeg veka na ovom se području stvorila lingvistička i kulturna simbioza različitih balkanskih etničkih grupa: Albanaca, Slovena, Turaka i Arumena. U savremenoj balkanistici je širom priznato da je područje gde se danas presecaju albanska, makedonska i grčka granica, bilo i jeste sada centar pojave i distribucije jezičkih inovativnih procesa koji su doveli do tako zvane balkanizacije jezika balkanskog jezičkog saveza (РуСАКов-СоБолев 2008: 14). Kako tvrdi J. Lindstedt: „Centar balkanizama se nalazi, kako se čini, negde malo južnije od Ohridskog i Prespanskog jezera gde su se sreli grčki, albanski, makedonski, arumunski i romski jezik" (LiNDSTEDT 2002: 332). Varijante balkanskih jezika u regionu Prespa zaista pokazuju više sličnosti u gramatičkoj strukturi.

Stanovništvo Prespe je tokom cele istorije ovog regiona bilo etnički raznovrstno. Arheološki nalazi govore o prisutstvu ljudi na tom području već u trećem mileniumu pre naše ere (ГЕоргиЕвА 2008). U V veku pre naše ere područje današnje Gornje i Donje Prespe ulazi u sastav Stare Makedonije koja se nalazila, zahvaljujući filelinskoj politici staromakedonskih careva, pod snažnim uticajem starogrčke civilizacije. U II veku pre naše ere Makedoniju zauzima vojska Rimskog carstva odnosno ova zona postaje centar preklapanja kultura različitih grčkih i paleobalkanskih (staromakedonskih ${ }^{6}$ i ilirijskih) plemena (KATIČIĆ 1976), a kasnije elinističke, rimske i vizantijske kulture (HAMmOND 1993, HAMmOND 2007). O paleobalkansim (Libino, Drim), grčkim (Geramidnica, Kambanarija) i latinskim/romanskim (Kaštel, Kambanarija) elementima u toponomastici Ohridskog područja v. kod P. Hr. Ilijevskog (Илиевски 1988: 414-543).

${ }^{5}$ U balkanskoj geografiji Prespanska zona se obično deli na dva dela: Gornja Prespa i Donja Prespa. U doba osmanskog vladanja kotlina je bila podeljena u administrativnom pogledu na Resensku i Donjeprespansku nahiju. Gornoj Prespi pripadaju sela na istočnoj i zapadnoj obali Velikog prespanskog jezera (ili Velika Prespa), a isto tako i Resensko Polje. Donjoj Prespi pripada zona ka jugu Velikog jezera i celo područje oko Malog prespanskog jezera (Mala Prespa) (ПЈAHКA 1970).

${ }^{6} \mathrm{U}$ radovima makedonskih istoričara danas se često govori o paleobalkanskom poreklu savremenog slovenskog naroda Makedonaca. U akademskoj „Istoriji makedonskog naroda” etnogeneza Makedonaca se prikazuje kao rezultat simbioze i asimilacije paleobalkanskog etnosa Starih Makedonaca od strane Slovena koji su došli na Balkan u VI veku (ЧЕПРЕГАНОВ 2008: 88). 
Sloveni dolaze na Balkan krajem VI veka i delimično asimiliraju lokalno stanovništvo koje se u to doba sastojalo od romanizovanihi elinizovanih paleobalkanskih plemena. Zemljište gde se danas nalaze Bitolj, Ohrid, Kičevo, Veles i čitav region Gornja Prespa, naseljava slovensko pleme Verziti (Цвијић 1911, АнАтољАК 1985, ШувАлов 1998; о najstarijim spomenicima slovenskog pisma u Prespi v. ИванОВ 1970: 55-63).

Tokom srednjeg veka Prespa je bila jedan od najznačajnijih političkih i strateških regiona na Balkanu. Krajem X i početkom XI veka, tokom vladavine cara Samuila, ovo područje pripada najvećoj srednjovekovnoj državi balkanskih Slovena - Prvog bugarskog carstva (ИА 2006: 66) u koje je spadalo čitavo Balkansko poluostrvo. Prespa postaje važan kulturni i duhovni centar sa prestonicom na ostrvu Sv. Ahil (o najstarijem od starobugarskih natpisa [natpis cara Samuila] v. ИвАНОВ 1986: 26-27, ГЕОРГИЕв 2003).

Prema osmanskim defterima prvi predstavnici turskog etničkog elementa pojavili su se u Prespi u XVI veku (Соколски 2005). To su bili bivši oficiri ili službenici koji su dobili zemlju kao nagradu za službu ili u vezi sa novim obavezama za upravljanje ovim područjem. Kasnije su u Prespu dolazili i drugi predstavnici turskog sveta: duhovna lica, trgovci, poljoprivrednici, zanatlije i dr. Kao rezultat ovih migracionih procesa u XVII i XVIII veku turski etnički element se prilično proširio u ovoj zoni. Prema statistici od kraja XIX v. u nahijama Gornja i Donja Prespa je živelo 151061 stanovnika: 14370 Turaka, 12346 Albanaca i 22995 Arumuna (Кънчов 1900).

Prema istraživanju L. Jusufi antroponimički podaci srednjovekovnih osmanskih dokumenata svedoče da je naseljavanje Prespe od strane Albanaca počelo već u XV veku (Jusufi 2012).

U makedonskom delu regiona Prespa samo u 6 naselja (od 46) stanuje mešovito albansko-makedonsko stanovništvo: Krani, Nakolec, Grnčari, Arvati, Asamati i Gornja Bela Crkva. Ova se sela nalaze kompaktno na istočnoj obali Prespanskog jezera (osim sela Nakolec koje se nalazi na jugo-istoku).

Administrativni centar regiona je multietnički grad Resen. Prema rečima Hadži-Vasiljevića Resen i njegova okolina su dobili status grada samo sredinom XIX veka (ПЈАнкА 1970, ХАџИ-ВАСИљЕВИЋ 1927). U antičko doba ovde (na značajnom rimskom putu Via Egnatia) nalazilo se naselje Sciritiana (Цвијић 1911). Danas se grad nalazi na pravcu (na putu) Ohrid-Bitola i Ohrid-Korča. Kako se navodi u lokalnoj legendi „nova” istorija Resena počinje krajem XVII veka kad su stanovnici sela Dobrovo (2 kilometra južnije od Resena) svoje naselje zbog čestih pljački i sele se u bezbednija mesta, kao što je bilo selo koje se prvi put spominje u Slepčevskom kodeksu u XVI veku pod imenom Ресенъ (v. ЈовАновски 2005, ПјАнкА 1970, СЕлищев 1933). Danas je to najveće naselje u regionu, jedinstvena varoš. Makedonci su počeli da se masovno sele u Resen na početku XIX veka iz sela Podmočani, Bolno, Molevišta i dr. (ПЈАнкA 1970).

Glavna zanimanja stanovnika Prespe pre XX veka: je bilo stočarstvo (u planinskim predelima), ratarstvo i ribolov. Osim toga, stanovnici Prespe su se uvek bavili pčelarstvom, vinogradarstvom i voćarstvom. Danas se većina stanovništva 
bavi proizvodnjom jabuka koja je bila značajno olakšana izgradnjom posebnih sistema za navodnjavanje (ЈовАновски 2005: 24-26).

Zadnjih godina značajnu ulogu u privredi regiona počeo je da igra turizam. Prema našim zapažanjima na terenu etnička pripadnost nema veliki uticaj na raspodelu zanimanja. Baviti se različitim vrstama poljiprivrede, turizmom, zapošljavati se u administrativnom, prosvetnom, zdravstvenom ili trgovskom sistemu mogu predstavnici svih etničkih zajednica.

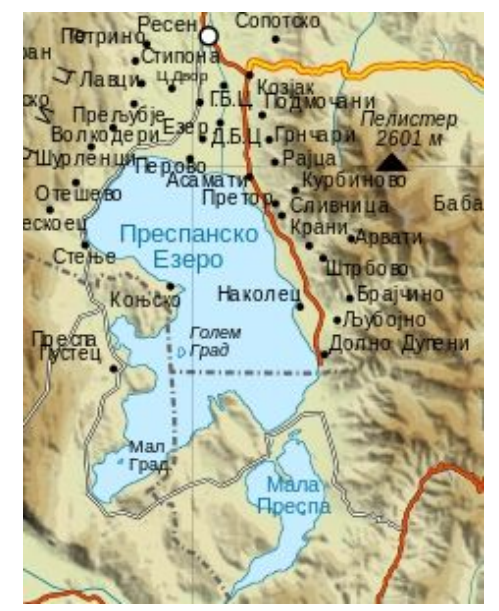

\section{Prespanski dijalekti makedonskog i albanskog jezika}

Opis makedonskog dijalekta Gornje Prespe je bio napravljen od strane B. Vidoeskog (Видоески 1998, МАрковиќ 2001). Međutim u makedonskoj dijalektologiji još nema ikakve monografije posvećene isključivo ovom dijalektu ili govoru nekog od prespanskih sela. Sest naselja ovog područja su bili izabrani kao punktovi Makedonskog dijalektskog atlasa (mak. Лескоец, Стење, Љубојно, Арвати, Претор, Царев Двор - МДА 2008).

Prema klasifikaciji makedonskih dijalekata B. Vidoeskog u zoni Donja Prespa prolazi granica između periferijske zapadne grupe i kostursko-lerinske grupe južnomakedonske dijalekatske zone. Opis govora Donje Prespe (mak. долнопреспански говор) v. u radovima bugarskog dijalektologa B. Šklifova (Шклифов 1979; v. takođe: Видовски 1998). Govor Male Prespe (Albanija) koji isto tako spada u donjeprespansku subgrupu ${ }^{7}$ je prikazan u radovima G. Cvetanovskog (ЦвЕТАновски 2010). ${ }^{8}$

\footnotetext{
${ }^{7}$ Albanski deo Prespe, to jest zapadna obala Velikog prespanskog jezera, zove se u makedonskoj geografskoj tradiciji Mala Prespa. Na ovom području se nalaze 8 sela: Tuminec, Gornja Gorica, Donja Gorica, Glombočeni, Šulin, Pustec, Leska, Zrnsko i Cerje. 2002.

${ }^{8} \mathrm{O}$ gornjeprespanskom i donjeprespanskom govoru u bugarskoj dijalektologiji v. Стойков
} 
Selo Krani je jedan od punktova Albanskog dijalektnog atlasa (ADGjSh). Opis albanskog govora Gornje Prespe je napravljen od strane Z. Osmanija (OsMANI 1995, Osmani 1996, Osmani 1997, Osmani 2001). Skupljanjem i analizom dijalektne leksike (sa posebnim osvrtom ka leksičkim pozajmicama iz makedonskog jezika) bavi se A. Poljoska (РоLOSKA 2003, Пољоски 2014).

Gornjeprespanski dijalekat makedonskog dijalektnog kontinuma kako po svojim fonetskim i fonološkim tako i po morfološkim i sintaksičkim parametrima zauzima središnju poziciju između periferijskih ohridsko-struških zapadnih govora i centralno-zapadnih govora koji su bili izabrani kao osnova makedonskog književnog jezika. Time se može objasniti činjenica da govornici prespanskog dijalekta u potpunosti vladaju kniževnim standardom i da na ovom području nije tipična (za razliku od nekih drugih makedonskih regiona) jezička situacija gde bi „,makedonski dijalekat X" bio suprotstavljen makedonskom književnom jeziku.

Ovde ćemo prikazati kratak opis najrelevantnijih sa tačke gledišta slovenske i albanske dijalektologije fonetičko-fonoloških i morfosintaktičkih diferencijalnih karakteristika. Navedeni primeri (u makedonskoj ćirilići) su uzeti iz našeg terenskog materijala, ${ }^{9}$ isto kao i iz makedonske dijalektološke naučne građe.

\begin{tabular}{|c|c|}
\hline Pojava & Primer \\
\hline $\begin{array}{l}\text { 1) Refleks nazala zadnjeg reda } *_{Q}> \\
{ }^{*} r_{Q} k a\end{array}$ & $\begin{array}{l}\text { [ə] } \\
p^{\prime} \kappa a^{10} \\
M^{\prime} \% \\
\text { з'б }\end{array}$ \\
\hline $\begin{array}{l}\text { 2) Refleks nazala prednjeg reda } *_{e}> \\
* m e ̨ s o\end{array}$ & $\begin{array}{l}{[\mathrm{e}]} \\
\text { месо }\end{array}$ \\
\hline $\begin{array}{l}\text { 3) Refleks slogotvornog sonanta } *_{r}> \\
*_{v r} b a\end{array}$ & $\begin{array}{l}{[ə r]^{11}} \\
\text { B'pбa }^{11}\end{array}$ \\
\hline $\begin{array}{l}\text { 4) Refleks slogotvornog sonanta } * l> \\
* v l k b\end{array}$ & $\begin{array}{l}{[\text { [oụ] }} \\
\text { [voukk] } \\
\text { волк }\end{array}$ \\
\hline $\begin{array}{l}\text { 5) Refleks jata *ě > } \\
\text { *bělb }\end{array}$ & $\begin{array}{l}\mathrm{e}] \\
\text { бел }\end{array}$ \\
\hline $\begin{array}{l}\text { 6) Refleks poluglasnika zadnjeg reda } *_{b}> \\
*_{s b n b}\end{array}$ & $\begin{array}{l}{[\mathrm{o}]} \\
\mathrm{COH}\end{array}$ \\
\hline
\end{tabular}

${ }^{9}$ 2014. godine u okvirima projekta za opis, proučavanju i upoređenju glagolskih formi (o ciljevima i metodu rada v. MАКАРОВA 2014) u govorima Prespanskog područja, naime u naseljima Resen, Arvat, Kran i Asamat bila su sprovedena dva terenska istraživanja. Sakupljen je jezički materijal od predstavnika različitih makedonskih, arumunskih i albanskih porodica. Iskorišćeni su sledeći etnolingvistički i sintaksički upitnici: ПлОТНИКОВА 1996, МДАБЯ 1997, МАКАРОВА 2014.

${ }^{10}$ Primeri u makedonskoj ćirilici su uzeti iz rada dijalektologa B. Videoskog (Видовски 1998).

${ }^{11}$ Distribucija vokala /ə/ u gornjeprespanskom dijalektu je relativno ograničena (za razliku od drugih zapadnomakedonskih dijalekata). Ovaj se vokal pojavljuje u govoru kao refleks nazala zadnjeg reda ili u sastavu grupe /ər/ dobijene kao refleks slogotvornog sonanta (z’əbi, g'ərlo) ali samo u korenskoj morfemi (ВидОЕСКи 1998, ИлиЕвСКи 1988: 99-113). 


\begin{tabular}{|c|c|}
\hline $\begin{array}{l}\text { 7) Refleks poluglasnika prednjeg reda } *_{b}> \\
* d b n \\
\text { 8) Refleks sekundarnog poluglasnika } *_{b_{2}}> \\
* \text { ognb }>*_{o g} n\end{array}$ & $\begin{array}{l}{[\mathrm{e}]} \\
\partial e H \\
{[ə]} \\
O{ }^{\prime} H\end{array}$ \\
\hline 9) Refleks suglasnika $* h(\text { posle } / u /)^{12}>$ & $\begin{array}{l}{[\mathrm{v}]} \\
Y_{B O}\end{array}$ \\
\hline 10) Refleks grupe $* t j>$ & 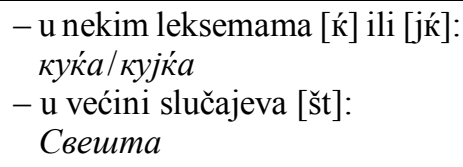 \\
\hline 11) Refleks grupe $* d j>$ & $\begin{array}{l}{[\check{\mathrm{z} d}]} \\
\text { Тужд }\end{array}$ \\
\hline $\begin{array}{l}\text { 12) Formant -oj }(<o b u) \text { za građenje oblika } \\
\text { množine jednosložnih imenica }\end{array}$ & лебој, ножеј \\
\hline $\begin{array}{l}\text { 13) Česta upotreba sintetičkih oblika dativa } \\
\text { (kod vlastitih imenica i termina srodstva) })^{13}\end{array}$ & $\begin{array}{l}\text { му даде Петрету, Марку } \\
\text { ја рекоф Марије, мајке }\end{array}$ \\
\hline $\begin{array}{l}\text { 14) Široka distribucija oblika posesivnog per- } \\
\text { fekta i perfekta tipa ,cyм oден”. Posesivni } \\
\text { perfekat se pojavljuje u većini resultativnih } \\
\text { i eksperijencialnih konteksta. }\end{array}$ & $\begin{array}{l}\text { 'eden čovek od t'uka 'ima nap'i- } \\
\text { sano kn'iga za n'ašeto s'elo. } \\
\text { mi r'ekoa d'eka s'obiraš m'arki. } \\
\text { d'ali 'imaš s'obrano mn'ogu do } \\
\text { s'ega? } \\
\text { a za pr'ošetki sum 'odena vo l'e- } \\
\text { rin, s'olun ne sum 'odena. v́o l'e- } \\
\text { rin, k'ostur, i bug'ariïa sum 'ode- } \\
\text { na, v'oden, t'amo sum 'odena, } \\
\text { so m'zžot mi, so k'olata... ama } \\
\text { mn'ogu b'evme m'ačeni, mn'ogu } \\
\text { pr'aevme, n'emavme n'išto. }\end{array}$ \\
\hline
\end{tabular}

Albanski dijalekti jugo-zapadne Makedonije (uključujući govor prepanskih Albanaca) spadaju u toskijsku dijalektnu grupu i pokazuju mnoge sličnosti sa idiomima severne toskijske zone (OSMANi 1996). Za svu severnotoskijsku dijalektu zonu je tipična slabo izražena fonetska i gramatička diferencijacija (ДЕсницКАЯ 1968: 260), pri čemu prespanski dijalekat albanskog jezika se odlikuje na leksičkom nivou za koji je karakteristična veća količina slovenskih pozajmica (PoLOSKA 2003). Vokalni sistem se sastoji od sedam fonema ( $a, e, \ddot{e}, o, u, i, y)$ kao što je slučaj za svu severnu toskijsku dijalekatsku zonu (OsMANi 1996: 19, Jusufi 2012: 173). U ovim govorima nema dugih a isto kao i redukovanih vokala. U govorima sela Kran i Gornja Bela Crkva se očigledno prati tendencija ka višoj vokalizaciji foneme $\ddot{e}$ ispred nazalnih suglasnika: dhembë, kengë (OSMANI 1996: 23, ADGjSh

\footnotetext{
${ }^{12}$ Na početku reči i u poziciji između dva vokala fonema /h/ propada (ВидоЕски 1998: 282).

${ }^{13}$ Arhaizam koji se može objasniti kontaktima sa neslovenskim balkanskim jezicima (ВидоЕски 1998: 114, ИлиЕски 1988: 99-113).
} 
1: 75). U nekim pozajmicama slovenskog porekla nalazimo $u$ na mestu $o$ u albanskom (gumë < gomë; рuтрё < pompë).

Konsonantni sistem u ovom dijalektu kao i na celom severnotoskijskom prostoru (ДЕсницКАЯ 1968, GJINARI 1989, OsMANi 1996) sastoji se od 27 fonema (odsutna je fonema $h$; nema suprostavljanja $r$ i rr: giua < gjuha; laesh <lahesha; rotë < rrotë; mar < marr). U nekim pojavama se sreće mešanje th i f: më jep një felë (< thelë) mish. Zvučni konsonanti na kraju reči se obezvučavaju: krimp < krimb; shkrump $<$ shkrumb. Važno je istaći da je i u makedonskom prespanskom govoru skoro nestala fonema / $\mathrm{h} /$ koja potpuno propada na početku reči i u položaju između dva vokala i prelazi u /v/ u položajima posle /u/, pa ispred suglasnika ili na kraju reči: мува, уво, суво, очув (ВидоЕски 1998: 282).

U oblasti morfologije imenica u ovom se govoru sreće jedna donekle arhaična crta, naime građenje oblika akuzativa imenica muškog roda uz pomoć nastavka në: shi-shinë; det-detnë; dhëmp - dhëmpnë (Osmani 1996: 64).

U glagolskoj morfologiji vidimo najveći broj razlika između prespanskog govora i ostalih dijalekata toskijske zone (koja inače nije naročito diferencirana) (ДЕсницКАя 1968: 276); ova činjenica odražava opštebalkansko odsutstvo postojanosti u građenju glagolskih osnova i različitih glagolskih oblika. Od tipičnih osobina glagolske morfologije prespanskog glagola navešćemo sledeće: varijante oblika jednine glagola jam: jeshe/jesha, jeshe, ishi; građenje forme: imperfekta prvog i drugog lica regularnih glagola uz pomoć nastavaka -nja i -nje: punonja, punonje; aorist se na isti način može graditi uz pomoć arhaičnog elementa -t: shkojta (v. OSMANI 1996: 90-91).

Funkcije glagolskih oblika u makedonskim i albanskim govorima Prespe prema našem terenskom istraživanju pokazuju visoki stepen izomorfizma i izofunkcionalnosti (što može da se posmatra kao jedan od dokaza postojanja opštebalkanskog glagolskog sistema - LINDSTED 2002). Stvaranje ovog sistema je najverovatnije išlo istim pravcem kao i pojava drugih balkanizama (koji podudara u jezičkoj strukturi u balkanskim jezicima različitog porekla): dva jezička sistema su tokom nekoliko vekova bila u užom kontaktu i zahvaljujući bi- i multilingviznu govornika tih jezika u kojima se stvorila gotovo identična gramatička struktura (pri tome što je leksički fond, ne računajući nekoliko hiljada opštebalkanskih leksema, ostao različit) (SANDFELd 1930, Schaller 1975, ACEHOBA 2003). Kao i u makedonskom dijalektu Prespe osnovne glagolske forme za naraciju su aorist i imperfekat. Nije potpuno jasan status forme admirativa u prespanskom govoru albanskog jezika. Prema Osmani forme kao što su dalkam najčešće se danas sreću u tekstovima narodnih pesama (OSMANI 1996: 99). Rezultati terenskog istraživanja sa gramatičkim upitnikom (upoređivanje makedonskog i albanskog glagolskog sistema u Prespi) pokazuju da u svim kontekstima gde se u makedonskom idiomu koristi $\pi$-perfekat $\mathrm{u}$ admirativnom značenju, $\mathrm{u}$ albanskom vidimo perfekat. Materijali narativa starijih stanovnika ovog regiona, koji nisu učili standardni albanski jezik u školi, ne daju nijedan primer gde bi se forma admirativa koristila u spontanom govoru. 


\section{Zapažanja o etnojezičkoj situaciji u dvojezičnim prespanskim selima: fenomen Arvati}

U okvirima projekta za proučavanju glagolskih sistema (МАКАРОВА 2014) u dijalektima prespanskih jezika za terensko dijalektološko istraživanje su bila izabrana dva planinska sela na istočnoj obali Prespanskog jezera: Krani (osnovna zanjimanja stanovništva su stočarstvo i proizvodnja jabuka) i Arvati (osnovno zanimanje stanovništva je stočarstvo). Ova se sela nalaze $2,5 \mathrm{~km}$ od obale Prespanskog jezera na nadmorskoj visini $987 \mathrm{~m}$ u podnožju planine Pelister.

Gradjđa se sakupljala u skladu sa osnovnim načelima koji se koriste u okvirima projekta МДАБЯ: snimanje autentičnih dijalekatskih tekstova uz korišćenje etnolingvističkog upitnika (ПлотниковА 1996) i rad sa gramatičkim programom koji sadrži više rečenica koje prikazivaju određene gramatičke fenomene: „Ova vrsta istraživanja zahteva informatore koji vladaju maternjim dijalektom i književnim jezikom i mogu da naprave jasnu razliku između jedne i druge forme svog govora" (МДАБЯ-СП 1997: 14).

Etnički sastav ispitanih sela:

1) $\operatorname{Arvati}^{14}$ (137 stanovnika: 51 Makedonac i 85 Albanaca), ${ }^{15}$

2) Krani (416 stanovnika: 103 Makedonca i 305 Albanaca).

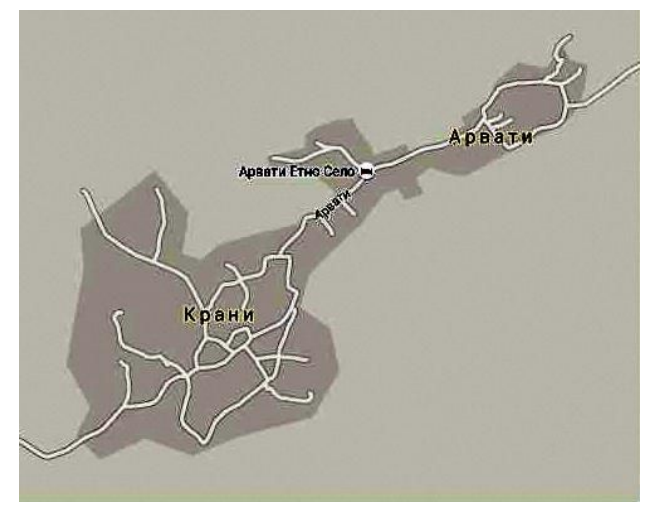

Albanci su u ovim selima muslimani. Oni posećuju jedinstvenu za oba sela džamiju (koja se smatra mestom formalne granice između ova dva sela, koja se inače nalaze toliko blizu jedno drugom da bi se moglo reći da je to već jedno naselje) i koristi jedinstveno muslimansko groblje.

Starija generacija Albanaca govori samo lokalni albanski dijalekat, lokalni makedonski dijalekat, književni makedonski jezik, srpsko-hrvatski i obično ne zna standardni albanski. Starija generacija Makedonaca (muškaraca) vlada lokalnim

\footnotetext{
${ }^{14}$ Selo Arvati se nalazi istočno od Krani na nadmorskoj visini 900 m. Ovo selo je mnogo manje od susednjeg: u njemu nikada nije bilo škole i deca su išla da uče u selu Krani. Kroz selo prolazi reka Šara na kojoj je do 60-ih godina funkcionisalo 9 mlinova (MoMEBA 2012).

${ }^{15}$ Ovde i dalje statistika se navodi prema ЈовАнОвски 2005.
} 
varijantima albanskog i makedonskog jezika i, osim toga, književnim makedonskim. Srednja i mlađa generacija Alabanaca vladaju i lokalnim dijalektima, i standardnim varijantima obaju jezika, koje se uče u školi. Kao što vidimo, jezička situacija u ovim selima je dosta neobična u odnosu na druge regione u Makedoniji. Albansko-makedonska dvojezičnost, koja se sreća u svim naseljima duž granice između Albanije i Makedonije, u ovim selima nema konfesionalnih prepreka.

U Kranu i Arvatu su predstavljene dve etničke i tri konfesionalne grupe: pravoslavci-Makedonci, muslimani-Albanci i mala grupa bektaša-Albanaca. ${ }^{16}$

Muslimani-Albanci (osim starijih žena), kao i na celom području Zapadne Makedonije, znaju oba jezika. Najinteresantnija činjenica jeste da čak i pravoslavciMakedonci pričaju albanski, što ne nalazimo drugim regionima Zapadne Makedonije što proizlazi iz naših terenskih zapažanja. ${ }^{17}$ Makedonsko-albanska dvojezičnost u Kranu i Arvatu je tipična samo za pravoslavne muškarce Makedonce svih generacija koji su se rodili i odrasli u ovim selima.

Jedan od mogućih razloga formiranja takve jezičke situacije je geografski položaj sela Arvati i Krani: naselja se nalaze visoko iznad Prespanske kotline, mnogo više od drugih sela ovog područja, i ranije, do izgradnje asfaltnog puta, ona su bila prilično izolovana od najvažnijih puteva i od adminisrativnog centra - Resena. Dakle, slovenska pravoslavna manjina nije imala mogućnost često napuštati selo i morala je da nauči jezik albanske muslimanske većine u stvari ona određivala na kojem se jeziku ostvaruje sva komunikacija unutar sela: na lokalnoj pijaci, u radnjama, na autobuskim stajalištima i u saobraćaju.

Žene-Makedonke u ovim selima, po pravilu, ne vladaju albanskim jezikom i slabo ga razumeju jer većina brakova je ekzogamna (makedonci starije i srednje generacije obično su tražili neveste $u$ drugim, monoetničkim selima Prespe).

Navešćemo funkcije obaju jezika u životu stanovnika Krana i Arvata:

1) Albanski jezik je osnovni jezik za komunikaciju u albanskim porodicama, deca ga obično nauče kao prvi u krugu porodice. Unutar sela ovaj se jezik koristi za komunikaciju sa komšijama: kako između Albanaca, tako i u govornim situacijama između Albanaca i makedonskih muškaraca. Isto tako se albanski jezik koristi za komunikaciju sa privremenim radnicima, vozačima putničkog i teretnog saobraćaja, u seoskom baru i slično.

U regionu Prespa albanski jezik nije službeni, dakle da sva oficijalna komunikacija u Resenu se seostvaruje na makedonskom jeziku.

2) Makedonski jezik u selima Kran i Arvat je osnovni jezik komunikacije unutar makedonskih porodica. Međutim, pošto su ove porodice predstavlaju manjina, komunikacija u selu se odvija na albanskom jeziku: muškarci ga obično nauče u ranom detinjstvu, prema rečima naših informatora, pa ga koriste ga tokom celog

${ }^{16}$ U Prespanskom području žive dosta velike grupe bektaša. Međutim najbliže teke se nalazi u Bitolju. U Krani i Arvati bektaši pričaju na albanskom jeziku, predstavnici bektaške zajednice u Resenu na turskom (СВетИевA 1993).

${ }^{17}$ Ponegde se može naći slučajevi kad muslimani-Makedonci (t. n. Torbeši) koji se često nazivaju Turcima, pričaju i albanski jezik (tako stoje stvari u Resenu i u nekim drugim prespanskim naseljima). 
života u svakodnevnoj komunikaciji sa komšijama Albancima. Ne naučiti albanski je bila „sramota”, prema jednom od naših informatora: mos mas'oš šk'ipə, t'urpu. ać p'opul k'ište škipt'ar 'Ako ne naučiš albanski, sramota, jer narod je bio albanski'.

Kao što je ranije istakao Weinreich, bilingvizam je najvažniji preduslov za realizaciju jezičkih kontakata. Danas postoje dva osnovna razumevanja šta je bilingvizam: prvo je strože, prema njemu bilingvizam je vladanje dvama jezicima na nivou maternjeg govornika (,native-like control of two languages” - BLOOMFIELD 1933: 55); drugo je šire: pod bilingvizmom se može razumevati bilo koji nivo vladanja drugim jezikom (,,praksa povremenog korištenja dvaju jezika”- ВАйнРАйх 1979); ili: „the point where a speaker can first produce complete meaningful utterances in the other language" (HAUGEN 1953: 7, ChIN-WigGLESworth 2007).

Niže je naveden primer govora na albanskom jeziku, koji je bio snimljen tokom intervjua sa dvojezičnim informatorom Ž. L., Makedonca, rođenog 1937. g. u selu Arvati. Informator vlada lokalnim makedonskim dijalektom, književnim standardom makedonskog jezika, lokalnim albanskim dijalektom, razume albanski književni jezik (pri gledanju albanskih kanala na televiziji). Smatrajući ovog informatora (i drugih makedonskih muškaraca iz sela Krani i Arvati) „,bilingvalnim” podrazumevamo drugi, širi pristup bilingvizmu. Očigledno je da je njegovo poznavanje albanskog jezika mnogo slabije nego kompetencija u makedonskom, koji je prvi po redu usvajanja i dominantni u njegovoj svesti (to jest to je njegov t. n. „maternji” jezik, pri tome što maternji jezik postoji kao uslovni pojam, njegova definicija nije toliko jednostavna: „Maternji jezik nije tačan sociolingvistički pojam i nema jasnog empirističkog referenta" - Вахтин 2001: 22). Dominantan položaj makedonskog jezika pojavljuje se uglavnom u kognitinom planu (to jest nivo poznavanja albanskog jezika je mnogo niže, tako da se u govoru pojavljuju mnoge „greške”, to jest interferencija makedonskog jezika).

Odgovor na pitanje koji jezik (albanski ili makedonski) jeste dominantan u funkcionalnom planu za stanovnike sela Arvati uopšte i posebno u slučaju ovog informatora nije nimalo jasan. Koristeći uveden od strane Fishmana i širom poznat pojam domena (domain, ,kontekst govorne delatnosti čoveka”, govorna situacija, socijalni kontekst razgovora - FisHMAN 1972), možemo reći da naš informator priča na albanskom jeziku u svim domenima osim porodice i društva drugih Makedonaca u selu. U ostalim situacijama (komšije-Albanci, radnje, pijaca, transport, seoska kafana i sl.) govori se na albanskom.

Tako opstaje u stvari za sve muškarce-Makedonce koji žive u selima Arvati i Krani. Uzimajući u obzir da svi Albanci takođe vladaju makedonskim jezikom, moglo bi se očekivati da će Makedonci koristiti svoj maternji jezik (državni i dominantni u maštabima na nivou čitave Makedonije) za komunikaciju sa svojim komšijama-Albancima (to je što je slučaj sa ženama-Makedonkama koje ne znaju albanski). Međutim iz nekoh razloga ovo se ne dešava, Makedonci više vole pričati na albanskom, što je, kako se može zaključiti iz intervjua sa informatorima, ,pitanje časti”" (vredi da se setimo ranije navedene reći Ž. L.: mos mas'oš šk'ipa, t'urpu. ać p'opul k'ište škipt'ar). Ovo se može smatrati svojevrstnim fenomenom (,fenomen Arvati”): slična jezička situacija u drugim regionima Makedonije se ne 
sreća. Prema rečima Ž. L. albanskim jezikom su takođe vladali njegovi deda i otac, majka koja je rođena u prespanskom selu Ljubojno pa nije znala albanski jezik nije znala, kao što ga ne zna ni žena našeg informatora (rođena u selu Brajčino).

U sudbini Ž. L. situacija apsolutne funkcionalne dominacije albanskog jezika je imala mesto samo u detinjstvu, koje je prošlo u doba Drugog svetskog rata. Tokom nekoliko sledećih decenija on je služio u jugoslovenskoj vojsci (u to doba dominantni jezik za njega je bio srpsko-hrvatski), zatim je radio u Skoplju i Bitolju (dominantni jezik je bio književni makedonski). Posle povratka u svoje selo nekoliko godina pre penzije $\breve{Z}$. L. ponovo se našao u albanskoj jezičkoj sredini i „setio se albanskog jezika” (prema njegovim rečima), koji je od tada ponovo postao funkcionalno dominantnim u njegovoj vlastitoj jezičkoj situaciji.

U naučnoj literaturi postoji nekoliko objašnjenja fenomena bilingvizma i više mogućih odgovora na pitanje šta je zapravo bilingvizam, u kakvim uslovima $i$ u kojim godinama treba naučiti jezik i na kom nivou ga je potrebno znati da bi se mogao smatrati bilingvom (za razliku od osobe koja poput maternjeg jezika vlada još jednim ili još nekolikim drugim jezicima) (CHIN-WigGLeSwORTH 2007: 5-20). Dosta često u svojstvu jednog od najvažnijih uslova bilingvizma navodi se uzrast usvajanja drugog jezika. Smatra se da je zapravo dečiji uzrast (do šest godina) jeste osnovna činjenica uspešnog i prirodnog učenja drugog jezika koji obezbeđuje tečnost (slobodu u izražavanju misli čak i pri nesaveršenom vladanju jezikom) (CHINWigGLESWORTH 2007: 13). Upravo takva situacija (usvajanje jezika u uzrastu do šest godina) bila je slučaj našeg informatora:

.... u r'ita me šipt'ar. arv'at k'išste ńi kind štop'ia. triviet 'išsin maked'on štop'ia, štatviet štipt'ar. mos mas'oš šk'ipa, t'urpu. ać p'opul k'ište škipt'ar.

...to loz'oi mund, a'ma to škruai jo. nga ato uml'autet će jan, me p'ika s'iper. ata s'di. kadoni'er gaboi.

kam ni pobrat'im, šok tim, un jam ńa k'ator p'es 'ora mi plak pe tij, ni dit jam $i$ l'indur. un jam l'indur špeit n'atən, p'ara to ngr'ira, ai d'itən ma šašt štat 'ora u lind. parp'ara n'eve k'išim m'otar, eve ai eve un. i ati i tij ervi na balaton - ata e k'išin štzp'in aty s'ipar na br'egu, vendin e... femi biral'ište na, se atje i mblivim ainvanet, pei fšati. ${ }^{18}$

Kao što se vidi, u govoru makedonskog informatora na albanskom jeziku nema fenomena koja se u literaturi po jezičkim kontaktima naziva mešanjem kodova (code-mixing). Prema P. Muyskenu mešanje kodova je pojava leksičkih ili gramatičkih osobina dvaju jezika u okviru jedne rečenice: mešanje kodova se suprostavlja preključivanju kodova (code-switching), to jest svesnom prelazu na drugi

18 'Odrastao sam sa Albancima. U Arvatu je imalo sto kuća. Trideset su bile makedonske, sedemdeset albanske. Ako ne naučiš albanski, sramota je. Narod je bio albanski... Da čitam mogu, ali da pišem ne. Tamo ima umlauta, sa tačkama gore. Ne zama ih. Ponekad pogrešim... Imam pobratima, moj drugar, ja sam stariji od njega od njega četiri-pet sati, istog dana sam se rodio. Rodio sam se noću, pred zoru, on - danju, u šest-sedam sati se rodio. Ranije smo imali sestre, i ja i on. I došli smo kod njega na obalu. Tamo su imali kuću, tamo, iznad obale, mesto... Zvali smo ga biralište. Tamo smo pasli stoku, daleko od sela... Stoku, biralište, tamo imaju kuću'. 
jezik (ili subvarijanta istog jezika) u procesu govorne delatnosti u zavisnosti od osobina jezičke situacije (v. MuYSKEN 2000). Weinreich je smatrao da su slučajevi prelaza na drugi jezik u okviru jedne rečenice jesu svedočanstvo nedovoljnog poznavanja tog jezika i mogu se smatrati kao interferencija. Najčešće se takva interferencija pojavljuje na leksičkom nivou. Ako bilingvalna osoba zaboravlja ili ne zna neku reč, svesno ili nesvesno koristi na njenom mesto reč iz drugog jezika. Informator Ž. V., kako smo videli, govoreći na albanskom jeziku u slučajevima poteškoća (što se izražava u dugim pauzama) koristi drugu strategiju: umest o korišćenja makedonskog ekvivalenta na mestu zaboravljene reči, trudi se da pronađe što bliži albanski sinonim. Međutim u gramatičkoj strukturi se mogu naći nekoliko primera kalkiranja makedonskih sintaksičkih konstrukcija: to loz'oi mund, a'ma to škruai jo ili neve k'išim m'otor.

Dalje je navedena lista nekih pojava gramatičke interferencije (prema Weinreichu, interferencija se ovde smatra kao neka promena u jeziku individuma izazvana kontaktom sa drugim jezikom). Od fonetičkih osobina vredi naročito spomenuti odsutstvo interdentalnih spiranata ('eve, 'ervi) (u nekim slučajevima ovo se može zapaziti u govoru prespanskih Albanaca - OsMANi 1996):

- informator ne koristi ili koristi ,nepravilno” padeže imenica i zamenica: aty s'ipar na br'egu;

- informator ne pravi razliku između oblika ata i ato: nga ato uml'autet će jan, me p'ika s'iper. ata s'di.

Tečni govor informatora pokazuje da njegova ,agramatična” interpretacija albanskog jezika ne sprečava uspešnu komunikaciju i njegovi sagovornici-Albanci ga potpuno razumeju. Istovremeno kao što se očekivalo, u govoru informatora se mogu sresti osobine koje su tipične za lokalni dijalekat (uglavnom, u leksici). $\mathrm{Na}$ primer, korišćenje predloga pe (stand. Alb. prej) u komparativnim konstrukcijama: un jam k'atar p'es 'ora mi plak pe tij.

\section{Zaključak}

Jezička situacija u dvojezičnim selima Prespanskog regiona u Makedoniji predstavlja jedan sociolingvistički fenomen. Bilingvizam - kao najvažnija karakteristika situacije etnokulturne simbioze dvaju ili više etnosa - ovde nema konfesionalnih prepreka. Za razliku od drugih multietničkih i multikonfesionalnih oblasti Makedonije gde muslimanski Albanci i pravoslavni Makedonci (ovde ne uzimamo $\mathrm{u}$ obzir regione simbioze muslimanskih Albanaca i muslimanskih Makedonaca, to jest Torbeša) žive u maksimalnoj fizičkoj i komunikativnoj izolaciji jedni od drugih (na primer, tipična je situacija kad se delovi naselja sa makedonskim i albanskim stanovništvom nalaze na različitim obalama reke, a u ulozi ,graničnog prelaza" igra most). Za albansko-makedonski bilingvizam u selima Prespe je karakteristično sledeće: relativno visoki nivo poznavanja albanskog jezika od strane makedonskih informatora, korišćenje albanskog jezika u svojstvu osnovnog sredstva za svakodnevnu komunikaciju, odsutstvo pojava mešanja kodova pri svakodnevnoj komunikaciji. 


\section{Literatura}

АНАТОљАК 1985 = АНАТОљАК С. Средневековна Македонија 1. Скопје, 1985.

АСЕНОВА 2003 = АСЕНОВА П. Балканско Езикознание. Основни проблеми на балканския езиков съюз. София, 2003.

БЕЛИКОВ-КРЫСин 2000 = БЕЛИКов В. И., КРЫСин Л. П. Социолингвистика. Москва, 2000.

ВАЙНРАЙХ 1979 = ВАЙНРАЙХ У. Языковые контакты. Состояние и проблемы исследования. Киев, 1979.

ВАХТин $2001=$ ВАХТин Н. Б. Языки народов севера в ХХ веке. Санкт-Петербург, 2001.

ВАХТИН-ГОЛОВКо 2004 = ВАХТИн Н. Б., Головко Е. В. Социолингвистика и социология языка. Учебное пособие. Санкт-Петербург, 2004.

ВидоЕски 1998 = ВидоЕски Б. Дијалектите на македнскит јазик. Т. 1-2. Скопје, 1998.

ГЕОРГИЕВ 2003 = ГЕОРГИЕВ П. Преспа. В кн.: Кирило-Методиевска Еничиклопедия. Т. 3. София, 2003. 327-331.

ГЕОРГИЕВА 2008 = ГЕОРГИЕВА А. Низ времето на Хераклеја Линкестис. Битола, 2008.

ГРАМАТНИКОВСКИ 1975 = ГРАМАТНИКОВСКИ В. Природно-географски, демографски и имотни карактеристики на Преспанската котлина. Скопје, 1975.

ДЕСНИЦКАЯ 1968 = ДЕСНИЦКАЯ А. В. Албанский язык и его диалекты. Ленинград, 1968.

ИА 2006 = ЧАКАРЈАНЕВСКИ Ѓ., ЧЕПРЕГАНОВ Т., ЈОТЕВСКИ В., ТОДОРСКА К. Историјски атлас. Скопје, 2006.

ИвАНОВ $1970=$ ИвАНОВ Й. Български старини из Македония. София, 1970.

ИвАНОВ 1986 = ИвАНОВ Й. Българите в Македония. София, 1986.

ИлИЕВСКИ 1988 = ИЛИЕВСКИ П. Хр. Балконолошки лингвистички студии. Со посебен осврт кон историскиот развој на македонскиот јазик. Скопје, 1988.

ЈовАНОВСКИ 2005 = ЈовАНОВСКИ В. Населбите во Преспа. Местоположба, историјски развој и минато. Скопје, 2005.

Кънчов 1900 = Кънчов В. Македония. Етнография и статистика. София, 1900.

МАКАРОВА 2014 = МАКАРОВА А. Л. Анкета для изучения модальных и темпоральных категорий глагола в языках БЯС. Македонски јазик LXV. Скопје, 2014. 285-302.

МДА $2008=$ ГАЈдовА У. и др. (ред.) Македонски диалектен атлас. Пролегомена. Скопје, 2008.

МДАБЯ-СП 1997 = СОБОЛЕВ А. Н., ВОРОНИНА И. И., ЛОПАШОВ Ю. А., РУСАКОВ А. Ю. МДАБЯ. Синтаксическая программа. Санкт-Петербург, 1997.

Микулчик 1996 = Микулчик И. Средневековите градови и тврдини во Македониа. Кн. 5. Скопје, 1996.

ПЈАНКА 1970 = ПЈАНКА В. Топономастика на Охридско-преспанскиот базен. Скопје, 1970.

ПлотниковА 1996 = ПлотниковА А. А. Материаль для этнолингвистического изучения балканославянского ареала. Москва, 1996.

Пољоски 2014 = Пољоски А. Лексичка интерференција на македонскиот и албанскиот дијалектен јазик. Скопје, 2014.

РУСАКОВ-СОБОЛЕВ 2008 = РУСАКОВ А. Ю., СОБОЛЕВ А. Н. СУбстанционально-функииональная теория балканского языкового союза и славянские языки. Доклад. XIV международный съезд славистов (Охрид, Македония, 10-16 сентября 2008 г.). Санкт-Петербург, 2008. 
СветиевА 1993 = СветиевА А. Бекташите (Бегинци) во Преспа како верска и етничка заедница. Етнолог 3. Скопје, 1993. 101-113.

СЕЛИЩЕВ 1933 = СЕЛИщЕВ А. М. Македонские кодики XVI-XVIII вв. София, 1933.

Сиьиновиќ 1987 = Сиьиновиќ М. Езерата во Македонија. Скопје, 1987.

СОБОЛЕв 2013 = СоБОЛЕВ А. Н. Основы лингвокультурной антропогеографии Балканского полуострова. Т. 1. Ното balcanicus и его пространство. Санкт-Петербург-München, 2013.

Соколски 2005 = Соколски М. Турски документи за историја на македонскиот народ. Опиирни пописни дефтери од XV век. Т. 2. Скопје, 2005.

СТОЙков 2002 = Стойков С. Българска диалектология. София, 2002.

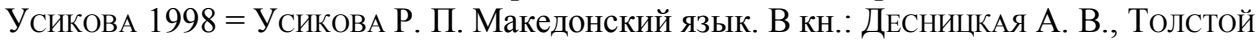
Н. И. (ред.) Основы балканского языкознания. Языки балканского региона. Ч. 2. Славянские языки. Санкт-Петербург, 1998. 156-189.

ХАџИ-ВАСИљЕВИЋ 1927 = ХАџИ-ВАСИљЕВИЋ Ј. Ресен и његова околина. Браство 21 (1927): 40-55.

ЦВеТАНОВСКИ $2010=$ ЦвеТАНОВСКИ Г. Говорот на македонц̧ите во Мала Преспа Западнопреспански говор. Скопје, 2010.

Цвилић 1911 = Цвијић Ј. Основе за географију и геологију Македоније и Старе Србије. Књ. 3. Београд, 1911.

ЧЕПРЕГАНОВ 2008 = ЧЕПРЕГАНОВ Т. (ур.) Историја на Македонскиот народ. Скопје, 2008.

Шклифов 1979 = Шклифов Б. Долнопреспанският говор. София, 1979.

ШувАлов 1998 = ШувАЛов П. В. Проникновение славян на Балканы. В кн.: ДЕсницКАЯ А. В., Толстой Н. И. (ред.) Основы балканского языкознания. Языки балканского региона. Ч. 2. Славянские языки. Санкт-Петербург, 1998. 5-28.

ЯРцЕВА 1990 = ЯРцЕВА В. Н. (ред.) Лингвистический энцииклопедический словарь. Москва, 1990.

ADGjSh = Guinari J., Beci B., ShKurtaj Gj., Gosturani Xh. Atlasi dialektologjik i gjuhës shqipe. Vëllimi I-II. Napoli-Tiranë, 2007-2008.

Bloomfield 1933 = Bloomfield L. Language. Chicago, 1933.

Chin-Wigglesworth 2007 = Chin Ng Bee, Wigglesworth Gillian: Bilingualism. An Advanced Source Book. New York, 2007.

DEMIRI 2005 = DEMIRI S. Einführung in die aktuelle politische und soziale Lage Makedoniens. In: Makedonien. Prägungen und Perspektiven. (Forschungen zu Südosteuropa.) Wiesbaden, 2005. 153-157.

DÖPMAN 2005 = DÖPMAN H.-D. Die religiöse Entwicklung Makedonies. In: Makedonien. Prägungen und Perspektiven. (Forschungen zu Südosteuropa.) Wiesbaden, 2005. 1331.

FISHMAN $1972=$ FISHMAN J. A. The relationship between micro- and macrosociolinguistics in the study of who speaks what language to whom and when. In: PRIDE J. B., HoLMes J. (ed.) Sociolinguistics. Selected Readings. Harmondsworth, 1972. 15-32.

GJINARI 1989 = GJINARI J. Dialektet e gjuhës shqipe. Tiranë, 1989.

Hammond $1993=$ Hammond N. G. L. Sources for Alexander the Great . Cambridge, 1993.

HAMmOND 2007 = HAMmOND N. G. L. Three Historians of Alexander the Great. Cambridge, 2007.

Haugen $1953=$ Haugen E. The Norwegian Language in the America. A Study in Bilingual Behaviors. Bloomington, Indiana, 1953. 
HiLl 2002 = Hill P. M. Makedonisch. In: Wieser Enzyklopädie des europäischen Ostens. Bd. 10. Lexicon der Sprachen des europäischen Ostens. Klagenfurt/Celovec-WienLjubljana, 2002. 295-313.

JuSUFI 2011 = JuSUFI L. Die zentralgegische Mundartgruppe in Mazedonien. Wiesbaden, 2011.

JuSUFI 2012 = JUSUFI L. Historische Migrationen im Spiegel der Dialektlandschaft von

Manastir in Mazedonien. In: Albanische Forschungen. Bd. 32. Aktuelle Fragestellungen und Zukunftperspektiven der Albanologie. Akten der 4. Deutsch-Albanischen kulturwissenschaftlichen Tagung ,50 Jahre Albanologie an der Ludwig-Maximilians-Universität München“. Wiesbaden, 2012. 167-182.

KAHL 2005 = KAHL Th. Ethnische Gruppen in der Republik Makedonien und ihre demographischen Eingenschaften. In: Makedonien. Prägungen und Perspektiven. (Forschungen zu Südosteuropa.) Wiesbaden, 2005. 57-81.

KATIČIĆ 1976 = KatičIĆ R. Ancient Languages of Balkans. The Hague-Paris, 1976.

LINDSTEDT $2002=$ LINDSTEDT J. Is there a Balkan Verb System? In: Balkanistika. Vol. 15. Papers from the Third Conference on Formal Approaches to South Slavic and Balkan Languages. Oxford, Miss., 2002. 323-336.

MeIer 2005 = MeIer V. Constitutional Order and Political Reality. In: Makedonien. Prägungen und Perspektiven. (Forschungen zu Südosteuropa.) Wiesbaden, 2005. 169-173.

МомевА 2012 = МомевА АЛтИПАРМАКовСКА В. Селските населби и куќи во Потпелистерието. Културно наследство на Битолско-преспанскиот регион. Битола, 2012.

Muysken $2000=$ Muysken P. Bilingual Speech. A Typology of Code-Mixing. Cambridge, 2000.

ORTAKOVSKI $2001=$ ORTAKOVSKI V. T. Interethnic Relations and Minorities in the Republic of Macedonia. Skopje, 2001.

Osmani 1995 = Osmani Z. Sistemi foljor i së folmes shqipe të Prespës. Shkup, 1995.

Osmani 1996 = Osmani Z. E folmja shqipe e Prespës. Shkup, 1996.

OSMANi 1997 = OsMani Z. E folmja shqipe e Manastirit dhe e qarkut të tij. Shkup, 1997.

Osmani $2001=$ Osmani Z. Prespa dhe zhvillimi $i$ arsimit shqip. Shkup, 2001.

PolosKa 2003 = PolosKA A. Leksiku dialektor në regjionin e Prespës. Shkup, 2003.

SANDFELD 1930 = SANDFELd K. Linguistique balkanique. Problèmes et résultats. Paris, 1930.

SCHALler 1975 = Schaller H. W. Die Balkansprachen. Eine Einführung in die Balkanphilologie. Heidelberg, 1975.

SCHRAMEYER 2005 = SCHRAMEYER K. Makedonien - ein Stabilitätsfaktor? In: Makedonien . Prägungen und Perspektiven. (Forschungen zu Südosteuropa.) Wiesbaden, 2005. 157169. 